\title{
Mitigation of Input Ripple Current in Single Phase Fuel Cell Power Systems
}

\author{
Soumya Sinha, Wajiha Shireen, and Sumit Pramanick \\ University of Houston, Texas, United States \\ Email: ssinha6@uh.edu
}

\begin{abstract}
Fuel cells serve as clean, renewable and an efficient source of electrical energy. The power conditioning system associated with their applications consists of a DC-DC Converter stage and a DC-AC inverter stage. In a single-phase fuel cell system, the single-phase inverter introduces a second harmonic component in the current drawn from the fuel cell source. This low-frequency current ripple has been found to be detrimental to the performance, lifespan, and efficiency of the fuel cell, if not adequately controlled. The paper presents a single loop current control method for the DC-DC converter stage that reduces the input current ripple drawn from the source in the single-phase fuel cell system. Simulations are carried out using MATLAB; the results compared with the conventional method. To validate the proposed approach, experimental results from a laboratory prototype are presented. The proposed method uses a Digital Signal Processor for control system monitoring and control.
\end{abstract}

Keywords: Fuel cell, second harmonic current ripple, DC-DC boost converter, power electronics, single phase inverter.

\section{Introduction}

With the increase in demand for electrical power generation, there has been an increase in the usage of fossil fuels. The depletion of these non-renewable sources of energy has necessitated the use of renewable energy sources, like wind energy, solar energy, fuel cells, tidal energy-to name a few. Fuel cells are one of the cleanest sources of energy and are being used for transportation, stationary and portable power applications. Since these are single-phase applications, the power conditioning system associated with the fuel cell stack is a DC-DC converter connected to a DC-AC Single Phase Inverter. The DC-AC stage introduces a second harmonic ripple current which gets imposed on the fuel cell. This low order current ripple reduces the lifetime of fuel cells, deteriorates their performance and hence, decreases the overall efficiency. It can reduce the fuel cell output power by $6 \%$ due to internal losses, and cause an increase in the distortion of its terminal voltage [1], [2], [3]. Thus, there is a need to mitigate the second order ripple component in the fuel cell input current. A lot of research work to reduce the ripple element has been conducted till date. The work in [4] adds an active filtering circuit across the DC-DC converter to supply an equal magnitude second harmonic current component with complementary phase. [8] uses an LC series resonance circuit tuned to twice the output frequency connected in parallel to the DC bus capacitor in a pulse width modulated voltage source inverter. Similar methods of using an active filter for current ripple reduction were proposed in [9] and [10]. Although the methods mentioned above can reduce the low order ripple current efficiently, yet the addition of an external circuit, large capacitor or high-power switches may result in an increase in cost, power losses and system complexity. The reliability of the system is also affected. [11] suggests a waveform control scheme to mitigate the lowfrequency current ripple. [12] puts forward a model predictive control strategy for second order harmonic reduction which tries modifying the duty cycle to minimize the second harmonic current. Another alternative way to eliminate the ripple is to adopt a control strategy such that the DC- bus capacitor supplies the entirety of the second harmonic current, leading the input current ripple to approach zero. [13] proposes a load current feed-forward (LCFF) control mechanism to modify the bus capacitance to supply the inverter input current. However, the control scheme is suggested for Buck Converter. Most of the industrial applications such as portable power generation from fuel cells, automotive body electronics 
and lighting system, space and avionics, wireless communication systems-to name a few, require a DCDC converter to boost up the voltage. Fuel cells also find use in residential and business applications such as HVAC heating, ventilation, and air-conditioning systems. [13] also suggests that the presence of an input inductor in a DC-DC Boost Converter can smoothen the input current by filtering out the ripple to some extent. But, the design of the inductor while keeping the system cost at a minimum, becomes challenging. Therefore, this research work focuses on a DC-DC boost converter in conjunction with a DC-AC Single Phase inverter. In this paper, a method to suppress the second harmonic current drawn from the fuel cell system is propounded. The proposed method: (1) does not require any additional circuitry in the power conditioning stage. (2) is less complicated as it involves only a single current control loop. (3) can be applied to the boost DC-DC converter stage used in most fuel cell applications. (4) helps maintain the system efficiency and reliability.

\section{Second Harmonic Ripple Current Generation in Fuel Cell based Power Electronic System}

Before explaining the ripple reduction method proposed by this paper, it is important to understand the power electronics circuitry involved with a fuel cell system and the cause of the low order ripple current. The output that can be achieved from a fuel cell is DC. Majority of the electrical loads require AC power for operation, which consequently augments a need for power conversion from DC to AC. A Power Electronic System(PES) is required to produce commercially usable AC power with the fundamental frequency of $60 \mathrm{~Hz}$. The fuel cell PES consists of a DC-DC converter connected to a DC-AC inverter which feeds the AC load as shown in Figure 1.

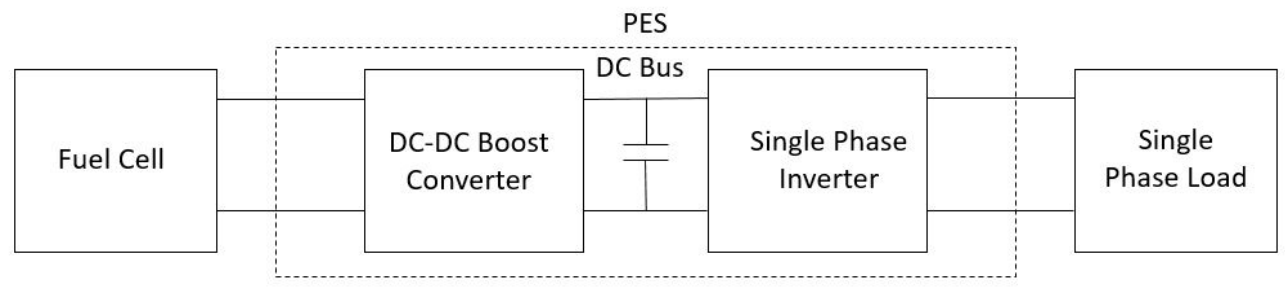

Figure 1. Conventional fuel cell PES

It is noteworthy to mention here that this research aims at low to medium power applications. As most of these applications require a higher output voltage, the Power Electronic System of the fuel cell employs a DC-DC boost converter. The following sections discuss the stages of the PES.

\subsection{Boost Converter Stage}

Figure 2 below shows a DC-DC Boost converter. A stepped-up output voltage, $V b_{\text {out }}$, is produced by controlling the switching of the high-frequency switch, S.

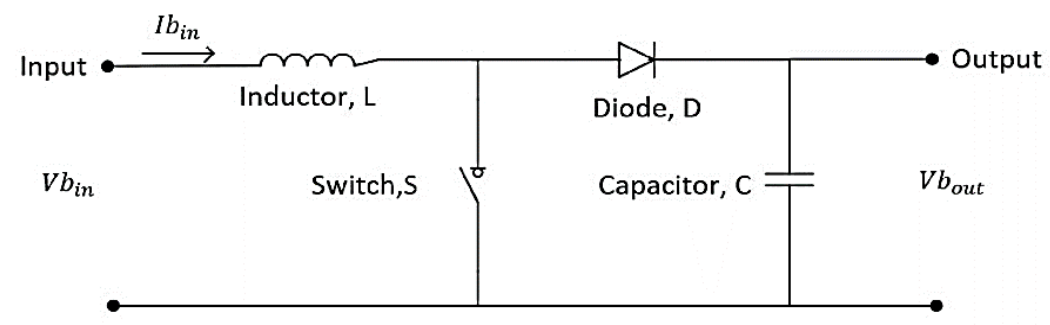

Figure 2. DC-DC boost converter

The ratio determining the output voltage of the boost converter [7] is expressed as,

$$
\frac{V_{b o u t}}{V_{b i n}}=\frac{T}{T_{o f f}}=\frac{1}{1-D}
$$

where $V b_{\text {out }}=$ Output voltage of the boost converter 
$V b_{i n}=$ Input voltage applied to the boost converter

$T_{\text {off }}=$ Switch off time

$T=$ Switching period

$D=$ Duty Cycle.

The boost converter switching frequency is kept at $20 \mathrm{kHz}$. The duty cycle of the converter is controlled by a conventional closed loop control system. This conventional control system will be discussed in detail in section 3 .

The boost converter input inductor is designed by the equation 2 as below:

where $L=$ Input inductor

$$
L=\frac{V b_{i n} * T}{\Delta i_{l}^{*} I b_{i n}}
$$

$V b_{i n}=$ Input voltage applied to the boost converter

$T=$ Switching period

$\Delta i_{l}=$ Current Ripple in the boost input inductor

$I b_{i n}=$ Boost converter input current.

Considering a power rating of $50 \mathrm{~W}$ with boost input voltage of $5 \mathrm{~V}$, the boost input current, $I b_{i n}$, is found as:

$$
I b_{i n}=\frac{\text { Power rating }}{V b_{i n}}=\frac{50}{5}=10 \mathrm{~A}
$$

Also,

$$
T=\frac{1}{f}
$$

where $V b_{i n}=$ Input voltage applied to the boost converter

$f=$ Switching frequency

$T=$ Switching period.

Substituting values from equation 3 and equation 4 in equation 2 and assuming the input current ripple, $\Delta i_{l}$, to be $1 \%$, boost input inductor, $\mathrm{L}$ is found as $250 \mathrm{uH}$.

Similarly, the capacitor can be designed by the equation 5 given below:

where $C=$ boost converter capacitor

$$
C=\frac{\text { Power rating }^{*} T}{\Delta V_{d c} * V b_{\text {out }}}
$$

$V b_{\text {out }}=$ Output voltage of the boost converter

$T=$ Switching period

$\Delta V_{d c}=$ Output Voltage Ripple in the boost converter.

Substituting the values of switching period, power rating in equation 5 and assuming the required output voltage and its ripple to be $50 \mathrm{~V}$ and $1 \%$ respectively, the capacitor, C's value is $450 \mathrm{uF}$.

\subsection{Single Phase Inverter Stage}

A full bridge single-phase inverter is shown in figure 3 below.

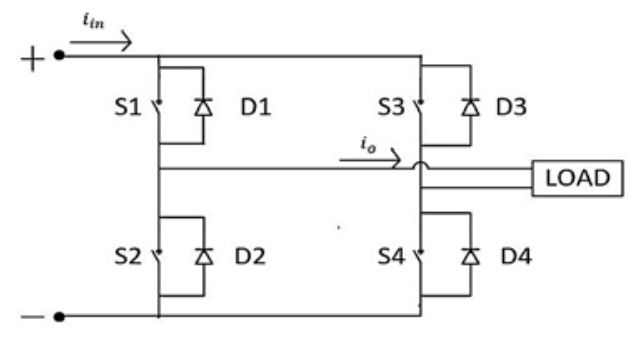

Figure 3. Single phase inverter 
As the name suggests, it provides a symmetrical AC output from a DC input. The switches of a branch are turned on complementarily to avoid short circuit of the DC bus. This means that highfrequency switches, S1 and S2 are never turned on at the same time and vice versa. The switches are controlled by bipolar pulse width modulating (BPWM) signals where the modulating signal, a sine wave, at the required output frequency, is compared with a high-frequency carrier wave, which is the triangular or saw-tooth wave. These signals have constant magnitude and frequency. The PWM signals, also called switching functions, are represented mathematically as Fourier series expressions. In order to ensure complementary switching pattern on the same leg, the switching functions for S1 and S3 are given by equation 6 and equation 7 below:

$$
\begin{gathered}
S 1=A_{n}+\sum_{n=1}^{\infty} A_{n} \sin (n \omega t) \\
S 3=A_{n}+\sum_{n=1}^{\infty} A_{n} \sin (n \omega t-n \pi)
\end{gathered}
$$

where $\omega=$ desired frequency at the inverter output in radians

$T=$ time variable

$A_{0}, A_{1}, A_{2} A_{3} \ldots \ldots . A_{n}$ are the Fourier series constants.

Also, the switching functions for switches S4 and S2 are the same as equation 6 and equation 7 respectively. The inverter is designed to work at the same frequency as the boost converter for easier hardware implementation. Accordingly, $20 \mathrm{kHz}$ is selected as the switching frequency for the inverter as well.

\subsection{Origin of Second Harmonic Component}

When a single-phase load is connected across the fuel cell PES, a second harmonic current flows through the system in addition to the fundamental current as shown in figure 4.

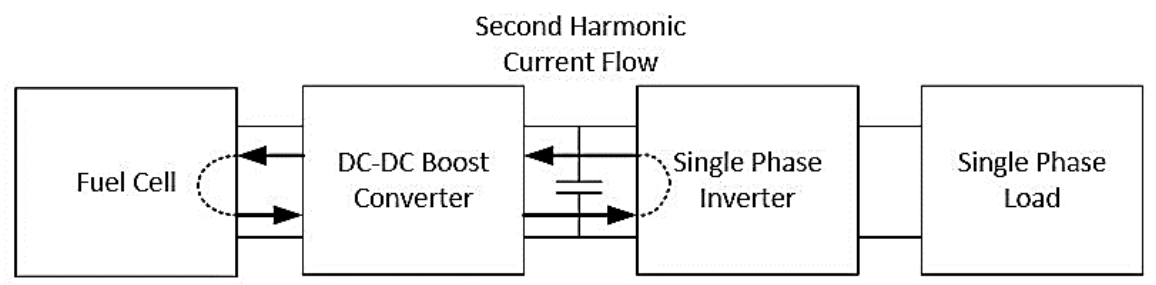

Figure 4. Second harmonic current flow in fuel cell PES connected to a single-phase load.

This part of the paper explains the cause of this current component in single-phase fuel cell system.

The inverter output current is modelled as a sinusoidal wave. Neglecting higher order harmonics for a Bipolar Pulse Width Modulation, the mathematical function for output current is

where $i_{o}=$ load Current

$$
i_{o}=I_{0} \sin (\omega t)
$$

$I_{0}=$ Amplitude of the load current

$\omega=$ inverter output frequency in radians.

Now, by using the switching functions from equation 6 and equation 7 , the inverter current through the switches S1 and S3 can be approximated as:

$$
\begin{aligned}
& I_{0} \sin (\omega t) \cdot \mathrm{S} 1=A_{0} I_{0} \sin (\omega t)+A_{1} I_{0} \sin ^{2}(\omega t) \\
& I_{0} \sin (\omega t) . \mathrm{S} 3=A_{0} I_{0} \sin (\omega t)-A_{1} I_{0} \sin ^{2}(\omega t)
\end{aligned}
$$

Equation 9 and equation 10 represent the current flowing through the inverter legs. The inverter input current, $i_{i n}$, can be obtained by subtracting equation 10 from equation 9 and is given as:

This simplifies to:

$$
\begin{gathered}
i_{i n}=I_{0} \sin (\omega t) \cdot \mathrm{S} 1-I_{0} \sin (\omega t) . \mathrm{S} 3 \\
i_{\text {in }}=2 . A_{1} I_{0} \sin ^{2}(\omega t)
\end{gathered}
$$


where $\omega=$ output frequency in radians

$$
i_{i n}=A_{1} I_{0}-A_{1} I_{0} \cos (2 \omega t)
$$

$$
\begin{aligned}
& T=\text { time variable } \\
& i_{\text {in }}=\text { inverter input current } \\
& A_{0}, A_{1} \text { are the Fourier series constants. }
\end{aligned}
$$

Hence, equation 13 shows that the single-phase inverter current has a second order harmonic current ( $2 \omega$ component) in addition to a DC component. This second harmonic current flows through the boost output side to its input and appears in an amplified form. It also flows through the fuel cell and affects its performance. Hence, it is essential to eliminate the second harmonic current component.

\section{Proposed System}

The previous section established mathematically the presence of the second harmonic current ripple (i.e., $120 \mathrm{~Hz}$ ) in a single-phase fuel cell power electronic system. This paper proposes a method which modifies the control system associated conventional fuel cell PES of figure 1. Hence, it is necessary to first understand the control system of the conventional fuel cell PES before delving into the proposed control system design.

\subsection{Conventional Control System}

In power system applications, the boost output voltage should be regulated. To do so the DC-DC boost converter is designed for closed loop control. Figure 5(a) and figure 5(b) show the conventionally closed loop control diagram for a boost derived fuel cell PES. The fuel cell is modelled as a DC source. $G_{v}$ is the voltage controller, and $G_{i}$ is the current controller. A Discrete Proportional-Integral (PI) controller, as shown in figure 6 , is employed to implement both the voltage and current controllers. Hence, $G_{v}$ is expressed as:

$$
G_{v}(z)=K_{p v}+\frac{K_{i v}}{z-1}
$$

where $K_{p v}=$ Proportional Constant

$K_{i v}=$ Integral Constant

Similarly, the transfer function for current controller is defined as:

where, $K_{p i}=$ Proportional Constant

$$
G_{i}(z)=K_{p i}+\frac{K_{i}}{z-1}
$$

$K_{i}=$ Integral Constant.

$G_{p w m}$ represents the gain of the pulse width modulator. Also, the DC-bus impedance transfer function is given as,

$$
G_{D C}(s)=\frac{1}{s C_{b u s}}
$$

In discrete time domain, the DC-bus impedance transfer function is,

where $C_{b u s}=\mathrm{DC}$ bus capacitance.

$$
G_{D C}(z)=\frac{z}{(z-1) C_{b u s}}
$$

The closed loop control maintains the boost output voltage at a constant value irrespective of the variation in system parameters. As can be seen from figure $5(\mathrm{~b})$, the output voltage, $V b_{\text {out }}$, is sensed and compared to a reference value, $V b_{r e f}$. The controller, $G_{v}$, takes the error in the two as the input signal and produces a current reference signal, $I_{r e f}$. The newly generated current reference, $I_{r e f}$ and 
the measured input current, $I b_{i n}$ are compared next. The output of the comparator feeds into the current controller, $G_{i}$ which outputs the duty cycle. The duty cycle is used to generate PWM signals which drive the switch $\mathrm{S}$.

To ensure that the steady state error is zero and the system dynamics is improved, $K_{i}$ and $K_{p}$ values for both the controllers are selected as below:

Voltage controller, $G_{v}: K_{p v}=1$ and $K_{i v}=10$.

Current Controller, $G_{i}: K_{p i}=5$ and $K_{i}=1000$.

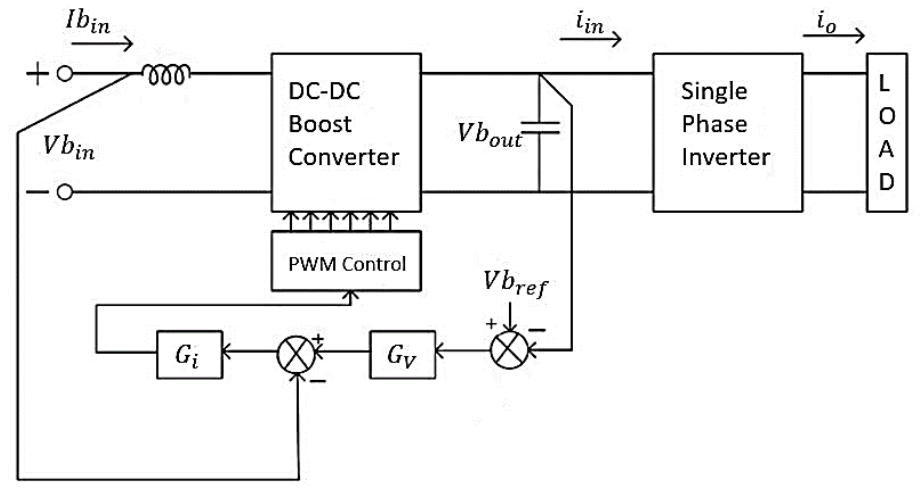

Figure 5(a). Conventional control system of a fuel cell PES

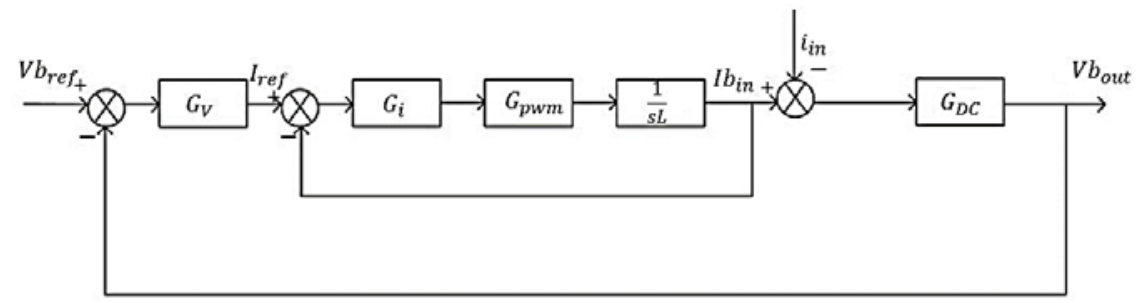

Figure 5(b). Equivalent control block diagram

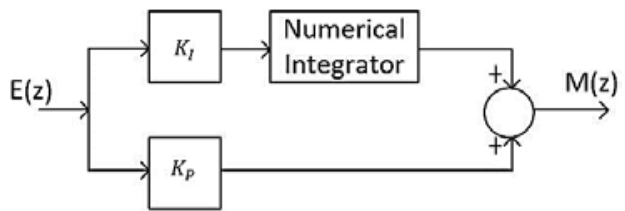

Figure 6. Discrete PI controller

\subsection{Proposed Control System}

Figure 7 below shows the proposed control system and its block diagram representation. The proposed method adds a second harmonic current feedback to the closed loop control system of figure 5 . The design parameters remain the same as those of the control system of figure 5. $G_{v}, G_{i}$ are the voltage and current controllers given by equation 14 and equation 15 respectively. $G_{p w m}$ represents the gain of the pulse width modulator. $G_{D C}$ is the DC-bus impedance transfer function defined by equation 16 . This paper proposes a single loop current control method to eliminate the $120 \mathrm{~Hz}$ current ripple by adding an equal magnitude of low order ripple to the DC Bus voltage. In other words, the DC-bus capacitor is made to supply the $120 \mathrm{~Hz}$ harmonic component, leaving the input current ripple free. [13] introduced a High Pass filter to compensate for the DC bias produced due to load current feed forward control by a continuous integral action of the DC-bus impedance function. However, the design proposed 
by this paper prevents the production of a dc bias voltage, thereby eliminating the need to add a high pass filter and reducing the complexity further.

The second harmonic current, $i_{2 n d}$, is extracted from the boost input current, $I b_{i n}$ by using a band pass filter(BPF). The low order current ripple is used to calculate the equivalent low order voltage ripple, $V_{2 n d}$. The boost output voltage reference changes to $V_{2 n d}+V_{\text {ref }}$.

Section 7 elaborates the proposed control system design. First, the band pass filter model is discussed, followed by the method used to extract the second harmonic current ripple. Finally, a subsection explains the steps involved in the generation of the time varying duty cycle to control boost converter switching.

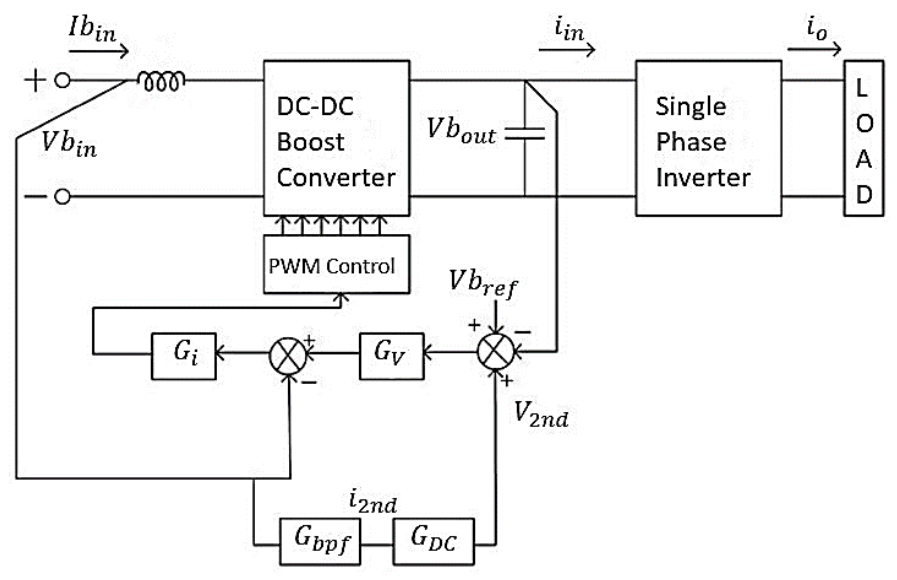

Figure 7(a). Proposed control system

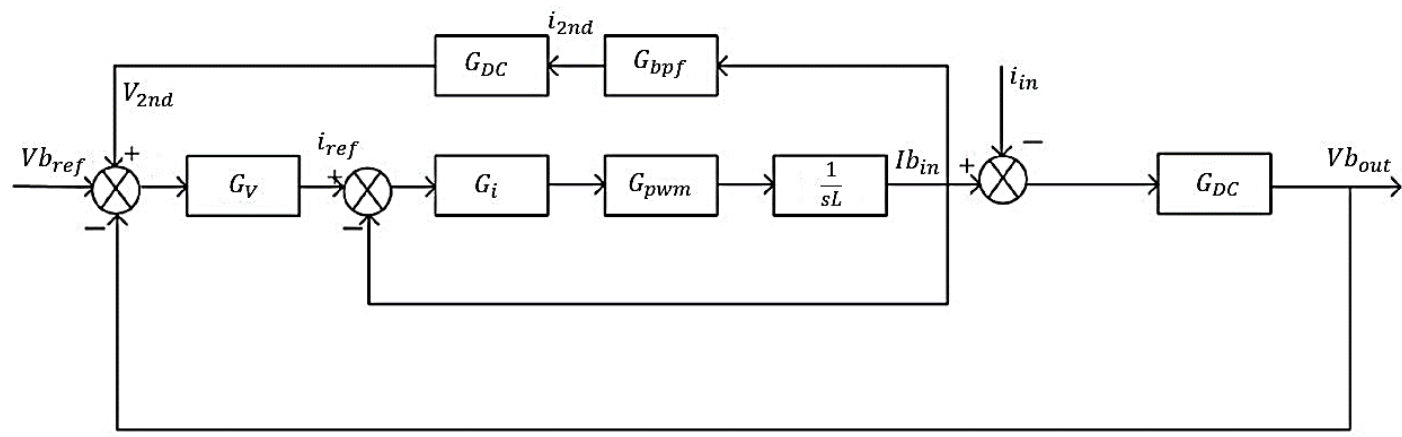

Figure $7(\mathbf{b})$. Block diagram representation of the proposed system

\section{Band pass filter design(BPF)}

A band pass filter is used to extract the second harmonic current (120 Hz component) from the boost input current. As the system runs in discrete time steps, the band pass filter must also work in discrete time domain. Also, the filter should allow signals only at the frequency of $120 \mathrm{~Hz}$. The BPF must reject all the other frequencies. The transfer function of the BPF in s-domain, $G_{b p f}(s)$, is given as:

$$
G_{b p f}(s)=\frac{\left(2 \omega_{b}\right) s}{s^{2}+\left(2 \omega_{b}\right) s+\left(\omega_{b}\right)^{2}}
$$

here, $\omega_{b}=$ bandpass frequency $=2 \pi 120$.

On substituting the value of $\omega_{b}$ and solving the above equation to obtain the z-domain form, the equivalent transfer function for $\mathrm{BPF}, G_{b p f}(z)$, is found to be:

$$
G_{b p f}(z)=\frac{2(z-1) \omega_{b}}{z^{2}-(1.926) z+(0.9274)^{2}}
$$


It can be inferred from the Bode plot of $\mathrm{BPF}$ in figure 8, the magnitude of the band pass filter is equal to $0 \mathrm{~dB}$ at a frequency of $120 \mathrm{~Hz}$ and relatively lower at other frequencies. The phase angle at this frequency equals $0^{\circ}$. Thus, the BPF can extract the second harmonics altogether, filtering out other components well.

\section{Extracting second harmonic ripple current}

This step helps in obtaining the second harmonic current component from the boost input current. The current flowing through boost input inductor is measured and passed through the BPF of equation 19 which extracts the second harmonic current ripple from it.

In other words,

$$
i_{2 n d}=G_{b p f}(z) I b_{i n}
$$

where $i_{2 n d}=$ second harmonic current on boost input side

$I b_{i n}=$ Boost converter input current

$G_{b p f}(z)=$ BPF transfer function (from equation 19).

The equivalent voltage ripple value, $V_{2 n d}$, is calculated from the second harmonic current ripple and the DC-bus impedance by employing Ohm's law.

Or, the voltage ripple is given as,

$$
V_{2 n d}=G_{D C}(z) i_{2 n d}
$$

where, $G_{D C}(z)$ and $i_{2 n d}$ are found from equation 20 and equation 21 respectively.

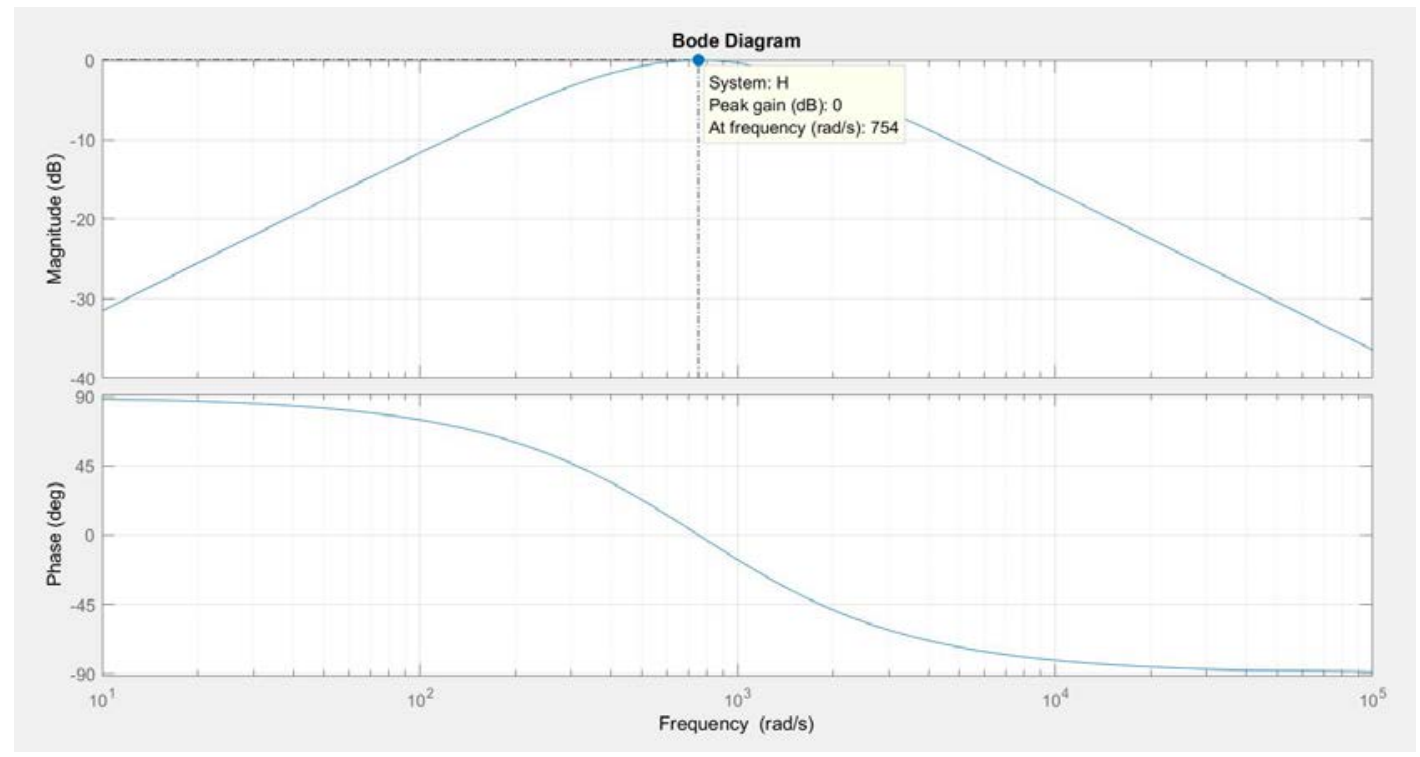

Figure 8. Bode plot of the band pass filter with $\omega_{b}$ of $2 \omega_{o}$.

\section{Generating new duty cycle for boost converter}

The second harmonic voltage ripple value generated from equation 21 is added to the DC-bus link voltage reference as shown in Figure 7. Similar to the working of the closed loop system (figure 5), the modified voltage reference signal is compared against the sensed boost output voltage, and the resulting signal is passed to Discrete Proportional Integral controller. The new current control variable generated is compared to the measured boost input current containing the $120 \mathrm{~Hz}$ component. The error signal serves as an input for another PI controller. The output of the PI controller produces the new duty cycle. The PWM switching of the boost converter is controlled depending on the new duty cycle generated. Thus, the $120 \mathrm{~Hz}$ current component from the input side is removed, thereby leaving the fuel cell current ripple free. 


\section{Simulation Results}

Simulations of both the conventional control system (figure 5) and the proposed control system (figure 7) are carried out in MATLAB-SIMULINK using discrete sampling time of lus. A DC source is used to model a fuel cell source. Boost switching frequency is kept at $20 \mathrm{KHz}$. The inverter switches utilized Sinusoidal Bipolar PWM. A $60 \mathrm{~Hz}$ reference sinusoidal wave is compared with $20 \mathrm{kHz}$ triangular carrier wave to generate the PWM signals. Also, modulation index for the single-phase inverter is kept at 0.8 .
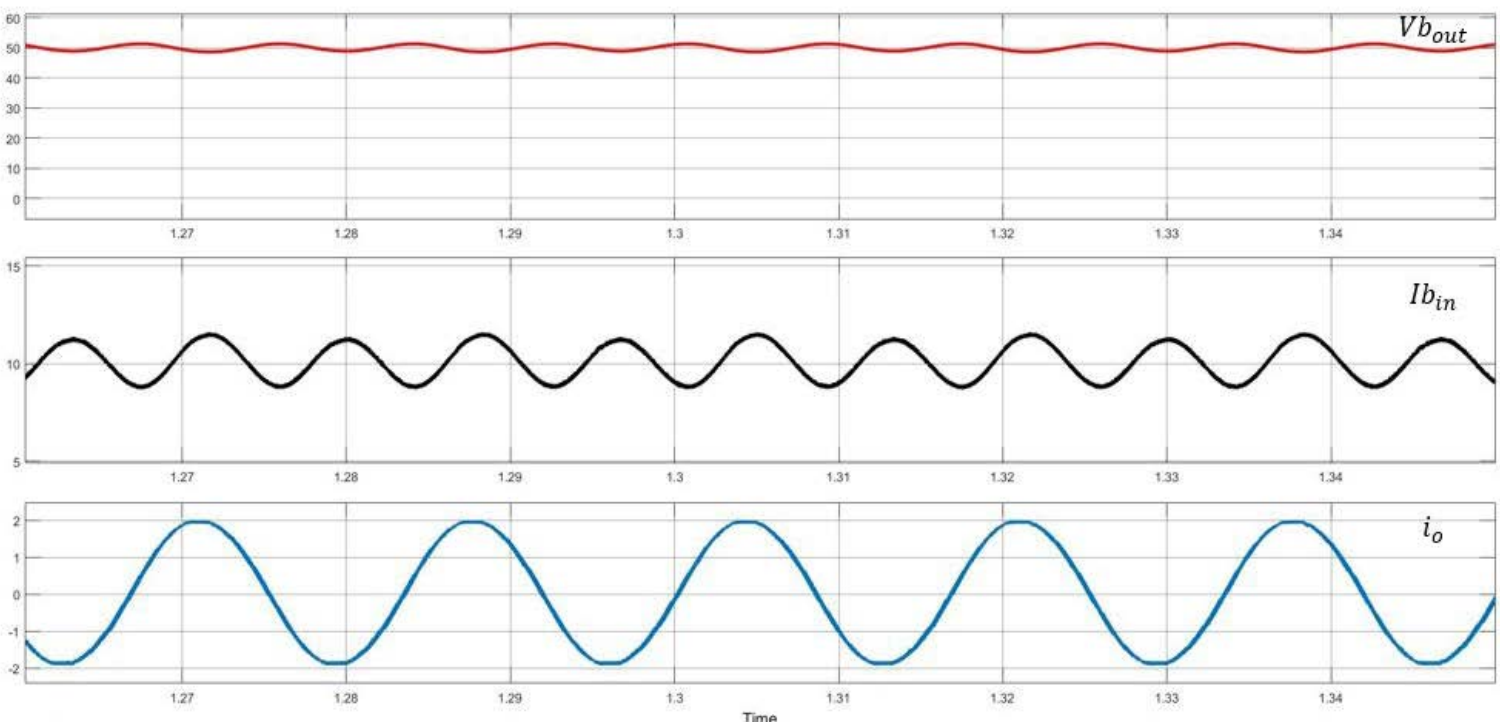

Figure 9. Simulation result of conventional PES; boost output voltage, boost input current and load current (top to bottom).
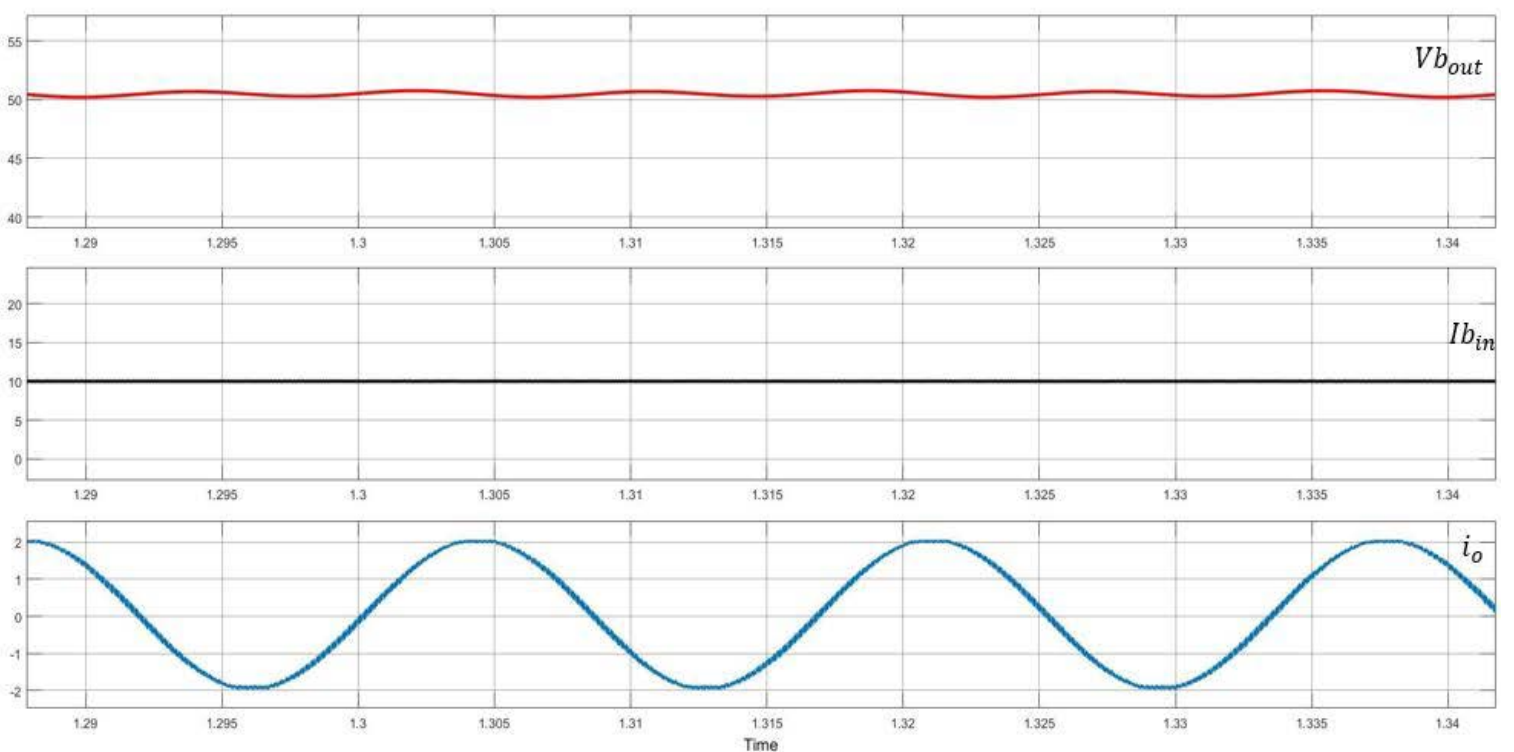

Figure 10. Simulation result of the proposed system; boost output voltage, boost input current and load current (top to bottom).

Figure 9 shows the time domain representation of the boost output voltage, boost input current (fuel cell current) and the inverter output current for a conventional fuel cell system. The inverter output current is a $60 \mathrm{~Hz}$ sinusoidal signal. Figure 9 shows that the fuel cell current (the boost input current) consists of a significant $120 \mathrm{~Hz}$ component riding on the DC value. Figure 10 shows boost output 
voltage, boost input current (fuel cell current) and the load current waveforms in the time domain for the proposed fuel cell system. It is evident from Figure 10 that the $120 \mathrm{~Hz}$ component has been eliminated from the fuel cell current (middle trace). Table 1 below lists the results from frequency Discrete-Time Fourier Transform(DTFT) analysis which further proves that the low order ripple has been eliminated from the input current significantly. Though some ripple can be seen riding on the boost converter output voltage, it is a small magnitude as shown by the DTFT analysis results presented in Table 1.

Table 1. FFT analysis

\begin{tabular}{|c|c|c|}
\hline Quantity measured & A typical PES of figure 5 & Proposed control system shown of figure 7 \\
\hline $\mathrm{Ib}_{\text {in }}$ & $65.28 \%$ & $2.89 \%$ \\
\hline $\mathrm{Vb}_{\text {out }}$ & $2.88 \%$ & $1.89 \%$ \\
\hline
\end{tabular}

Furthermore, the low order ripple current is limited to less than $5 \%$ and hence, meeting the criterion suggested by [14].

\section{$5 \quad$ Experimental Results}

To verify the effectiveness of the proposed method, the fuel cell system with the conventional PES of figure 5 and the modified PES with proposed control system of figure 7 has been realized on two-stage single phase inverter. The system is implemented for $50 \mathrm{~W}$ power rating. A $5 \mathrm{~V}$ DC source is used to model the fuel cell. The output voltage is controlled at $50 \mathrm{~V}$. An impedance of $0.5 \Omega$ and $5 \mathrm{mH}$ is selected at the output to ensure that the rated current flows through the boost input side. A digital signal processor forms the core of the control system. The boost output voltage, input current and load current waveforms are sensed and plotted using a mixed signal oscilloscope.

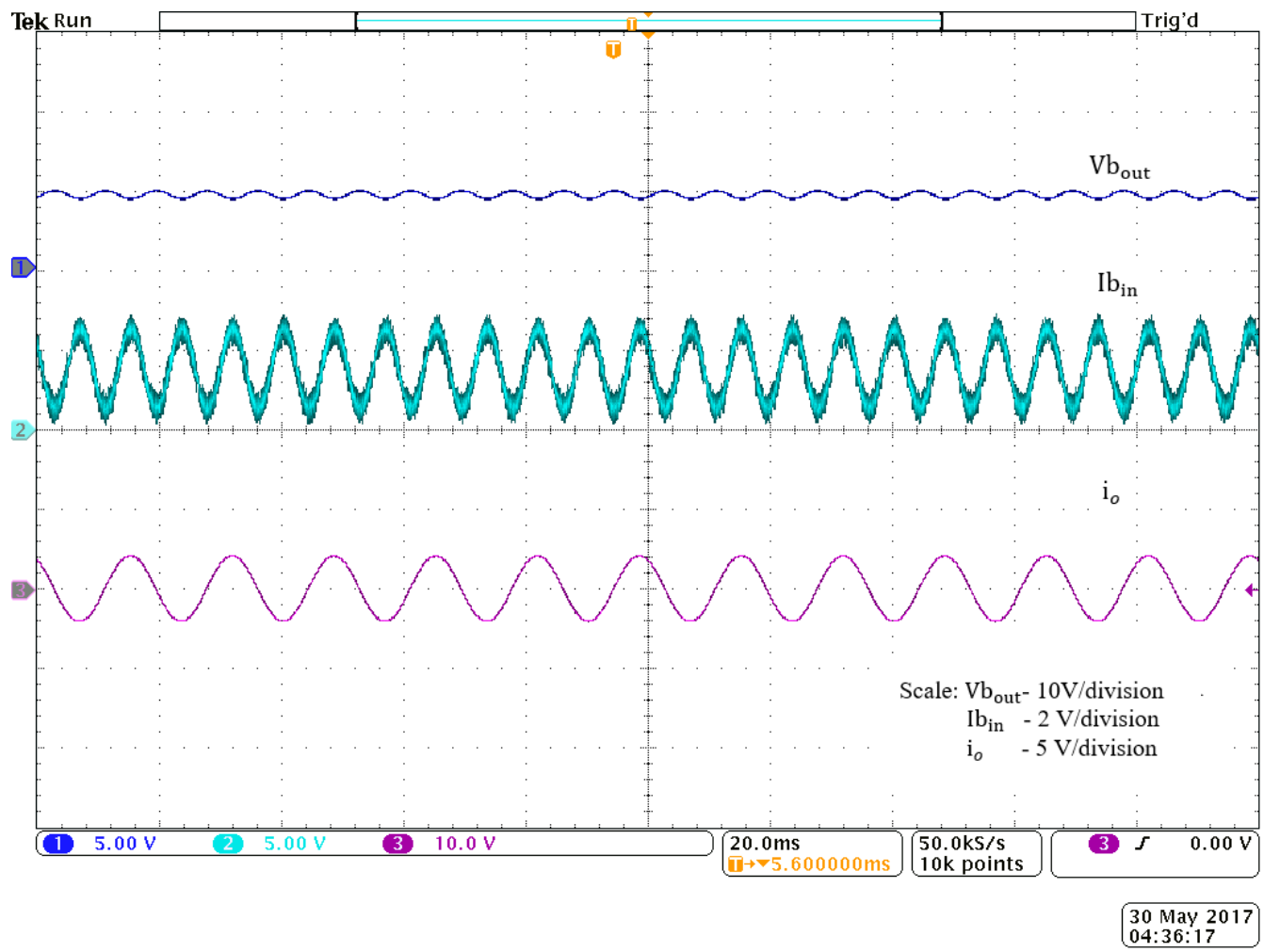

Figure 11. Experimental result for the conventional system; Boost output voltage, boost input current and load current (top to bottom). 


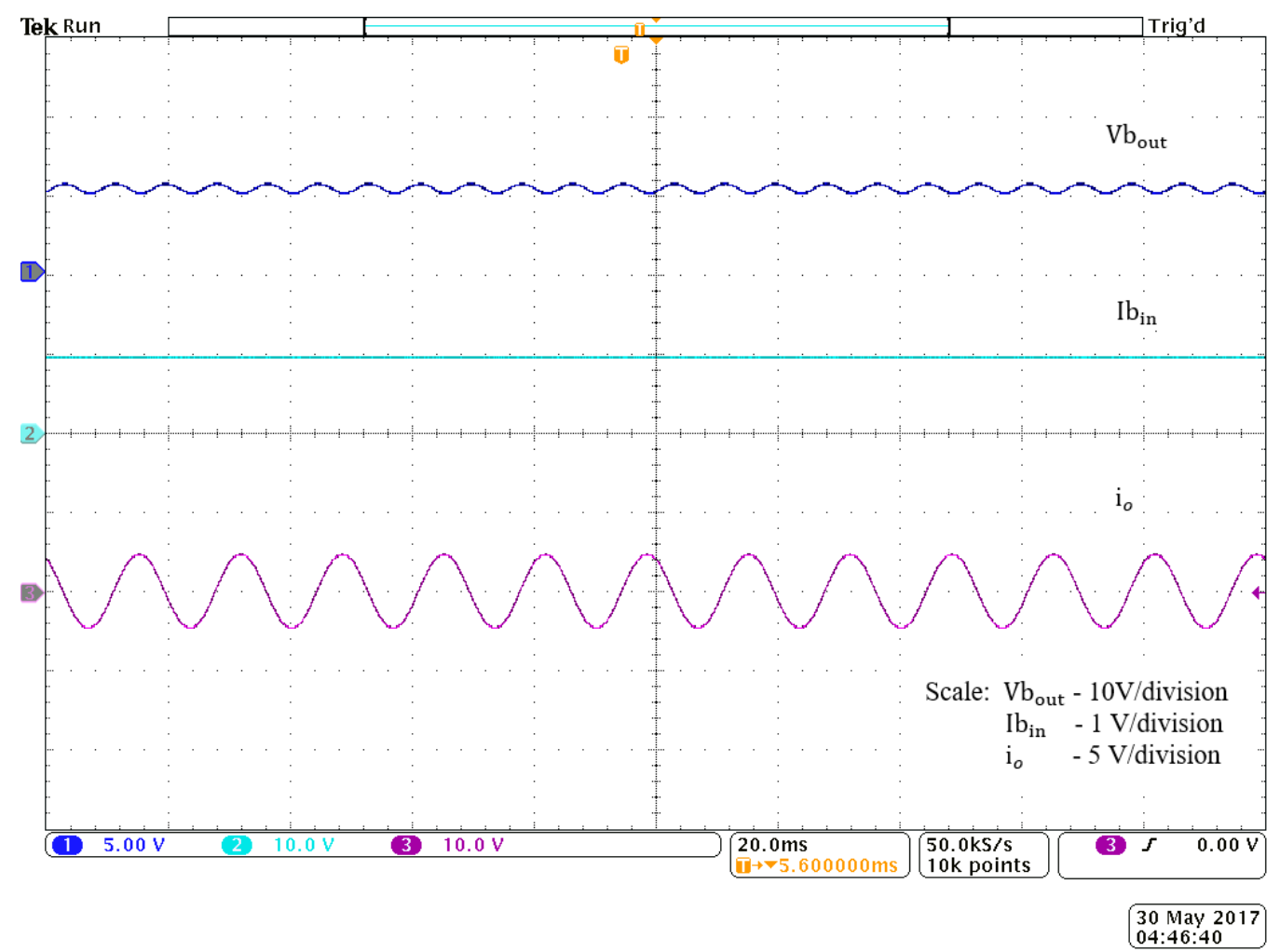

Figure 12. Experimental results for the proposed system; boost output voltage, boost input current and load current (top to bottom).

Figure 11 shows the boost output voltage, boost input current and the load current waveforms for a conventional closed loop fuel cell PES. The first trace of figure 11 corresponds to the boost output voltage, $V b_{\text {out }}$. The voltage scale is $10 \mathrm{~V} /$ division. Also, the measured value of the output voltage is 5 divisions. Therefore, the magnitude of the measured output voltage is:

$$
V b_{\text {out }}=5 \text { divisions } x \frac{10 \mathrm{~V}}{\text { division }}=50 \mathrm{~V}
$$

which matches the system requirements. The second trace of figure 11 corresponds to the boost input current or the fuel cell current, $I b_{i n}$. The scale is $2 \mathrm{~V} /$ division. The value of the measured from the graph corresponds to 5 divisions. Thus, the magnitude of the input current is,

$$
I b_{\text {in }}=5 \text { divisions } x \frac{2 \mathrm{~V}}{\text { division }}=10 \mathrm{~V}
$$

If the impedance of the oscilloscope probe is assumed to be $1 \Omega$, the input current magnitude is $10 \mathrm{~A}$, which corresponds to the design criteria of rated input current. The third trace of figure 11 is the load current, measured on the output of the single-phase inverter, $i_{o}$. The scale of the graph is $5 \mathrm{~V} /$ division. The load current is oscillating at the fundamental frequency of $60 \mathrm{~Hz}$. The boost input current (second trace) is oscillating at twice the fundamental frequency with a large amplitude. In other words, the input current has a significant magnitude of the low order current ripple. Further, the boost output voltage (third trace), is also oscillating at $120 \mathrm{~Hz}$, but the magnitude is small and does not affect the performance of the overall system. The percentage of the input ripple current is found to be $66 \%$ of the DC component, which closely agrees to the simulation result.

Figure 12 illustrates the boost output voltage, boost input current and the load current waveforms for proposed system. The analysis made for figure 11 holds true for figure 12 as well. The first trace of figure 12 corresponds to the boost output voltage, $V b_{\text {out }}$. It has been scaled to $10 \mathrm{~V} /$ division. Also, the measured value of the output voltage is 5 divisions. Therefore, the magnitude of the measured output voltage is: 


$$
V b_{\text {out }}=5 \text { divisions } x \frac{10 \mathrm{~V}}{\text { division }}=50 \mathrm{~V}
$$

again, a match of the system requirements. The second trace of figure 12 corresponds to the boost input current or the fuel cell current, $I b_{i n}$. The scale is $1 \mathrm{~V} /$ division. The value of the measured from the graph corresponds to 10 divisions. Thus, the magnitude of the input current,

$$
I b_{\text {in }}=5 \text { divisions } x \frac{2 \mathrm{~V}}{\text { division }}=10 \mathrm{~V}
$$

Considering the impedance of the oscilloscope to be $1 \Omega$, the input current magnitude is $10 \mathrm{~A}$, again satisfying the design criteria of rated input current. The third trace of figure 11 is the load current, measured on the output of the single-phase inverter, $i_{o}$. The scale of the graph is $5 \mathrm{~V} /$ division. The load current is oscillating at the fundamental frequency of $60 \mathrm{~Hz}$. It can be seen from figure 12 that the boost input current (second trace) is no more oscillating at twice the fundamental frequency. It is a DC value of $10 \mathrm{~A}$ with a negligible amount of low order ripple. Hence, the control system proposed by this paper is successful in eliminating the second order ripple from the input current. Additionally, the boost output voltage (third trace), shows an insignificant change in the low order voltage ripple. The percentage of second order ripple in the input is calculated to be approximately $3 \%$. Thus, the simulation results and the experimental results agree with one another.

\section{Discussion of Results}

This section analyses the results obtained from both the simulation and the experimental implementation. The simulation of the conventional fuel cell PES of figure 5 delineates an appreciable amount of second harmonic ripple on the input current. The Discrete-Time Fourier Transform (DTFT) analysis shows that this value was $65.28 \%$ of the DC component. In order to verify the presence of the ripple current, the system of figure 5 is executed experimentally using a digital signal processor. The outcome of the experimental implementation (figure 11) complies with those obtained from simulation, thereby, supporting the presence of a significant second order harmonic in input current. Such a high magnitude of low order current ripple is detrimental to a fuel cell, affecting its lifetime, performance and reliability. Hence, there is a motivation to design a control system for mitigating the $120 \mathrm{~Hz}$ input current ripple which is shown in figure 7. The proposed system is tested both by simulation and laboratory experiment to verify it's working. It can be clearly seen from figure 10 that the boost input current has a negligible amount of ripple after the proposed design is implemented. The DTFT analysis shows the magnitude of this ripple to be $2.89 \%$ of the DC component. Strictly speaking, there is a $95 \%$ reduction in the input current ripple. The experimental data (figure 12) also backs up this claim. Besides, the DC bus voltage ripple in the proposed has a minor variation in magnitude from the conventional fuel cell PES. Thus, the proposed system is robust and does not affect the system performance adversely. Moreover, though there are some trade-offs in the simulation parameters and the experimental implementation, yet the results obtained from both are comparable.

\section{Conclusion}

To solve the problem of input current ripple in single-phase fuel cell power systems, a single loop current control method is proposed for the DC-DC boost converter stage. The proposed method does not require any additional circuitry and the DC-DC converter control is designed such that the input ripple current is supplied by the DC-bus capacitor. The DC-DC converter input side is left ripple free. The proposed control is analysed and simulated in MATLAB, and the simulation results are presented. Experimental results from a laboratory prototype are presented showing that the proposed approach reduces the second harmonic current ripple from $65.28 \%$ to $2.88 \%$. The proposed system, after its performance optimization, can contribute significantly to increasing the life, efficiency, and reliability of fuel cell systems. Specifically, such a system can be targeted for low to medium power residential applications. 


\section{References}

1. W. Choi, G. Joung, P. Enjeti, J. Howze, "An Experimental Evaluation of the effects of Ripple Current Generated by the Power Conditioning Stage on Protom Exchange Membrane Fuel Cell Stack", Journal of Materials Engineering and Performance, v 13, n 3, June 2004, p 257-64.

2. S. Mazumder, K. Acharya, C. Haynes, R. Williams, M. Spakovsky, D. Rancruel, J. Hartvigsen, R. Gemmen, "Solid-Oxide-Fuel-Cell Performance and Durability: Resolution of the effects of Power-Conditioning Systems abd Application Loads", IEEE Transactions on Power Electronics, v 19, n 5, September 2004, Distributed Power Generation, p 1263-1278.

3. Boddu Somaiah, Vivek Agarwal, Suman R. Chowdhary, Siddharta P. Duttagupta, K.Govindan, "Analysis and comparative study of pulsating current of fuel cells by inverter load with different power converter topologies", International Journal of Hydrogen Energy, v 36, issue 22, November 2011, p 15018-15028.

4. W Shireen, H R Nene, "DSP based control for reliable fuel cell power systems with ripple current compensation", Power and Energy Society General Meeting - Conversion and Delivery of Electrical Energy in the 21st Century, IEEE 2008. pp. 1-4, IEEE, 2008.

5. W Shireen, H. R. Nene, "Active Filtering of Input Ripple Current to Obtain Efficient and Reliable Power from Fuel Cell Sources", Telecommunications Energy Conference, 2006. INTELEC '06. 28th Annual International. pp 1-6, IEEE, 2006.

6. http://www.mathworks.com/

7. D.W. Hart, "Introduction to Power Electronics, Prentice-Hall", Prentice-Hall, Upper Saddle River, NJ, 1997.

8. K.Harada, S. Nonaka, "FFT Analysis of the composite PWM Voltage Source inverter", Proceedings of the Power Conversion Conference-Osaka 2002 (Cat. No 02TH8579), 2002, pt. 2, p 1257-61 vol.3.

9. E. Santi, D. Fronzoni, A. Monti, D. Patterson, F. Ponci, N. Barry,"A fuel cell based domestic uninterruptible power supply", Conference Proceedings-IEEE Applied Power Electronics Conference and Exposition-APEC, v 1, 2002, p 605-613.

10. Y. Novaes, L. Barbi, "Low Frequency ripple current elimination in fuel cell systems", 2003 Fuel Cell Seminar, November 3, 2003, Miami, FL, p 21-26.

11. Guo-Rong Zhu, Siew-Chong Tan, Yu Chen, Chi K. Tse, "Mitigation of Low Frequency Current Ripple in fuelcell inverter systems through waveform control", IEEE Transactions on Power Electronics 28.2 (2013): 779-792.

12. Jin-Hyuk Park, Hae-Gwang Jeong, Kyo-Beum Lee, "Second order harmonic reduction technique using model predictive control for household energy storage systems", Applied Power Electronics Conference and Exposition (APEC), 2014 Twenty-Ninth Annual IEEE. IEEE, 2014.

13. Boujie Shi, Bangyin Liu, Shanxu Duan, "Low-Frequency Input Current Ripple Reduction Based on Load Current Feedforward in a Two-Stage Single-Phase Inverter", IEEE Transactions on Power Electronics 31.11 (2016): 7972-7985.

14. C. Liu and J.S. Lai, "Low Frequency current ripple reduction technique with active control in a fuel cell power system with inverter load", IEEE Transactions on Power Electronics 22.4 (2007): 1429-1436.

15. W Shireen, H.R. Nene, "Input ripple current compensation using DSP control in reliable fuel cell power systems", International Journal of Hydrogen Energy, v 37, issue 9, May 2012, p 7807-7813. 